\title{
Can initial resuscitation of preterm babies reduce the death rate from hyaline membrane disease?
}

\author{
M. I. A. OMER, „ EVELYN ROBSON, and G. A. NELIGAN \\ From the Princess Mary Maternity Hospital, Newcastle upon Tyne
}

\begin{abstract}
Omer, M. I. A., Robson, E., and Neligan, G. A. (1974). Archives of Disease in Childhood, 49, 219. Can initial resuscitation of preterm babies reduce the death rate from hyaline membrane disease? Retrospective analysis of the case records of 465 babies with a birthweight between $1.0 \mathrm{~kg}$ and $2.0 \mathrm{~kg}$, born during 1960-67, showed that $17.9 \%$ were described as 'blue' on arrival in the special care nursery, and that their mortality from hyaline membrane disease was $28.9 \%$ as compared with $6.8 \%$ in those described as 'pink'. The overall mortality from hyaline membrane disease was $10 \cdot 8 \%$. After the adoption of a policy of earlier use of oxygen under intermittent positive pressure, and more careful supervision of the environmental conditions during transfer to the nursery, the proportion of babies described as 'blue' on arrival fell to $5 \cdot 4 \%$ (a statistically significant improvement), and the overall mortality from hyaline membrane disease fell to $6.5 \%$ (not a significant improvement on the numbers available so far).
\end{abstract}

Granted that the death rate from hyaline membrane disease is inversely proportional to the baby's gestational age at the time of birth (Fedrick and Butler, 1970), other factors must explain why, at any gestational age, some babies are affected while others escape. Perinatal asphyxia has been suggested as one such adverse factor (James, 1959; Cohen, Weintraub, and Lilienfeld, 1960; Miller, 1962; Reynolds et al., 1965). This suggestion is supported by the observation that in liveborn twin pairs where at least one member is affected, the risk of developing the idiopathic respiratory distress syndrome, or dying of hyaline membrane disease, is many times greater in the second than in the first twin (Rokos et al., 1968; Neligan, Robson, and Hey, 1969). The subject was discussed by Avery (1968) who offered the forthright conclusion that $6 . .$. the therapeutic suggestion which arises from these observations . . . is to assist the onset of respiration by appropriate resuscitation in the delivery room'.

This paper reports the results of our investigation of this problem carried out in two stages. The first stage suggested that there was a clear relation between poor condition on arrival in the special care nursery and the risk of death from hyaline

Received 8 August 1973.

^Present address: Department of Paediatrics, University of Khartoum. membrane disease; and in the second were recorded and compared the results after adoption of a policy of improved immediate neonatal care.

\section{Methods and results}

Our interest in the problem was aroused by an alarming increase in the death rate from hyaline membrane disease in our hospital during 1966-67, at a time when the distance between the delivery suite and the special care nursery had temporarily been much increased by building work necessary for improvements in the hospital. We noted that an increased proportion of babies in the lowest birthweight groups were in poor condition on arrival in the nursery, and that the increased mortality from hyaline membrane disease appeared to be concentrated in such babies. We therefore decided to carry out a retrospective analysis of our case records to see if this association could be confirmed statistically.

First investigation. Our procedure concerning immediate neonatal care had been constant, at least in principle, since 1960 . During the previous year we had adopted as our standard procedure for assisting the establishment of respiration the use of oxygen under intermittent positive pressure through an endoctracheal tube, using a prototype or a production model of the 'Resuscitaire trolley'. Except in cases where the need for intervention was obviously urgent (unresponsive, pale baby with heart-rate less than 60 ), it was our policy to observe the effects of clearing the air-way, physical stimulation of fingers or toes, and a blast of oxygen 
directed at the baby's mouth, for a period of about 3 minutes before deciding to intubate. During the same year we made available a trolley-borne plastic 'hot box' in which selected babies could be transported to the nursery in an environment with a raised temperature and oxygen concentration. This was intended for the smallest babies, but no very clear policy was laid down for its use, and retrospective inquiry suggested that, particularly in 1966-67, individual residents had opted for speed of transfer at the expense of environmental conditions. We therefore decided to analyse the relevant case records for 1960-67. Because of the uncertainty concerning the gestational age of many babies, and the relatively small contribution of hyaline membrane disease to the mortality among babies of less than 28 weeks' gestation (Fedrick and Butler, 1970), we confined our analysis to those with a birthweight of between $1.0 \mathrm{~kg}$ and $2.0 \mathrm{~kg}$.

Our assessment of each baby's condition on arrival in the nursery was derived from the clinical description routinely written into the case notes by the nurse in charge at the time. This included a note of the baby's colour on arrival. In $6 \%$ of cases this was described as 'pale' only. Since this may be explained by anaemia, blood loss, or other conditions requiring specific methods of treatment, we excluded these cases from our analysis and confined it to the $94 \%$ who were either 'pink' or (centrally) 'blue'-conditions which may be influenced by the routine methods of respiratory and environmental assistance on which our investigation was focused.

Our assessment of the outcome included the clinical diagnosis of idiopathic respiratory distress syndrome made in the routine clinical records, but though this diagnosis was based throughout upon a written definition derived from the suggestions of Rudolph and Smith (1960), there is evidence of variation in the stringency of the diagnosis at different periods, and we have not included the analysis of the clinical results in this report. The results which we have included are based upon an assessment of the outcome in terms of the death rate from hyaline membrane disease, based upon the histological findings in cases where a necropsy was performed (86\%), and a clinical picture consistent with the diagnosis of respiratory distress syndrome in the remainder (14\%).

During the period of 8 years, 465 babies weighing between $1.0 \mathrm{~kg}$ and $2.0 \mathrm{~kg}$, born in this hospital were described as 'pink' or 'blue' on admission to the special care nursery. Of the 'pink', $6 \cdot 8 \%$, and of the 'blue', $28.9 \%$ died of hyaline membrane disease. The results are summarized in Table $\mathrm{I}$. The difference is highly significant $\left(P<0.001\right.$ by $\left.\chi^{2}\right)$.

This was convincing statistical confirmation that babies in poor condition on arrival in the nursery had a conspicuously increased risk of dying from hyaline membrane disease, and in order to improve the situation we needed to know more about the initial resuscitation and care of the babies who were 'blue' on arrival. We found that 32 of them had not been intubated at all, presumably because their respiratory function was considered by the paediatrician to be adequate. The average time elapsing from birth till they were recorded as 'pink' was $14 \cdot 8$ minutes. The remaining 51 had been
TABLE I

Death rate from hyaline membrane disease among babies with birthweight of $1.0 \mathrm{~kg}$ to $2.0 \mathrm{~kg}$ in 1960-67

\begin{tabular}{l|c|c|c}
$\begin{array}{c}\text { Clinical } \\
\text { group }\end{array}$ & $\begin{array}{c}\text { No. of } \\
\text { babies } \\
\text { (and \%) }\end{array}$ & $\begin{array}{c}\text { Deaths from } \\
\text { hyaline membrane } \\
\text { disease }\end{array}$ & $\begin{array}{c}\text { Death rate from } \\
\text { hyaline membrane } \\
\text { disease (\%) }\end{array}$ \\
\hline $\begin{array}{l}\text { Pink } \\
\text { Blue }\end{array}$ & $\begin{array}{r}382(82 \cdot 1) \\
83(17 \cdot 9)\end{array}$ & 26 & $\begin{array}{r}6 \cdot 8 \\
28.9\end{array}$ \\
\hline Total & $465(100 \cdot 0)$ & 24 & $10 \cdot 8$ \\
\hline
\end{tabular}

intubated, were recorded as 'pink' at an average of 12 minutes after birth, but had deteriorated again before arriving in the nursery. Of those who were 'pink' on arrival, half had been intubated and became pink at an average of 6.3 minutes after birth; the remainder became pink at an average of 3.2 minutes after birth. These results suggested that improvement was needed both in the initial resuscitation of babies at increased risk of hyaline membrane disease and in their care during transfer from the delivery room to the special care nursery.

Second investigation. We decided during 1970 when the results of the first investigation became available, to try to improve our procedures for the initial care of babies at increased risk of hyaline membrane disease, namely those who were considered to be preterm at the time of delivery or, if of uncertain gestational age, were considered to be of low birthweight. We tried to improve in two areas. (a) Intervene much earlier with assistance to respiration, aiming to achieve a good pink colour within 2 or 3 minutes of birth by administering $100 \%$ oxygen either by endotracheal tube if the baby's respirations were depressed, or by bag and mask if active spontaneous respirations rapidly established without improvement in colour. (b) Maintain baby's condition and colour meticulously during transfer to the nursery, leaving endotracheal tube in position in case of need and the paediatrician personally supervising the use of the 'hot box' with emphasis on good environmental conditions rather than speed of transfer.

The results of attempting to apply the new policy during 1971-72 are summarized in Table II.

The reduction in the proportion of babies described as

\section{TABLE II}

Death rate from hyaline membrane disease among babies with birthweight of $1.0 \mathrm{~kg}$ to $2.0 \mathrm{~kg}$ in 1971-72

\begin{tabular}{|c|c|c|c|}
\hline $\begin{array}{l}\text { Clinical } \\
\text { group }\end{array}$ & $\begin{array}{l}\text { No. of } \\
\text { babies } \\
\text { (and \%) }\end{array}$ & $\begin{array}{l}\text { Deaths from } \\
\text { hyaline membrane } \\
\text { disease }\end{array}$ & $\begin{array}{l}\text { Death rate from } \\
\text { hyaline membrane } \\
\text { disease }(\%)\end{array}$ \\
\hline $\begin{array}{l}\text { Pink } \\
\text { Blue }\end{array}$ & $\begin{array}{rr}87 & (94 \cdot 6) \\
5 & (5 \cdot 4)\end{array}$ & $\begin{array}{l}5 \\
1\end{array}$ & $\begin{array}{c}5 \cdot 7 \\
(20 \cdot 0)\end{array}$ \\
\hline Total & $92(100 \cdot 0)$ & 6 & $6 \cdot 5$ \\
\hline
\end{tabular}


'blue' from 17.9 to $5.4 \%$ is significant $(P<0.05$, $>0.01$ ), though there is some room for further improvement. The hope that the new methods of care achieved their objective is supported by the hyaline membrane disease mortality which was lower in the new 'pink' group than in the original one. As a result, there has also been a reduction in the overall mortality from hyaline membrane disease from $10 \cdot 8$ to $6.5 \%$, but with the numbers available during the 2 years, this difference is not statistically significant. Of all the babies in this weight group born during the 2-year period, $60 \%$ were initially treated with oxygen under intermittent positive pressure, as compared with $38 \%$ during the earlier 8 -year period.

\section{Discussion}

The results of these two investigations suggest that failure to establish optimal clinical condition as soon as possible after birth, and to maintain it during transfer to the special care nursery, is an adverse factor leading to an increased incidence of death from hyaline membrane disease in the preterm baby; and that deaths from this cause are largely preventable by earlier and better sustained application of simple routine methods of resuscitation and care. The improved results in 1971-72 cannot be explained by changes in the treatment of established hyaline membrane disease, since routine infusion of intravenous $10 \%$ dextrose by umbilical vein was introduced in 1960, supplemented by sodium bicarbonate when indicated, and prolonged intermittent positive pressure ventilation was introduced in 1962. Since hyaline membrane disease is by far the commonest cause of death among potentially normal newborn babies in this community (Fairweather et al., 1966), the importance of this observation is self evident.

It now seems likely that it is correct to adopt the same attitude towards early respiratory care as towards early feeding, namely that it is desirable to intervene actively relatively early in the case of the preterm baby, as compared with the term baby for whom a period of relative anoxia for some minutes after delivery, or of relative malnutrition for some days, can do no detectable harm. In the case of the preterm baby it seems desirable to use simple measures to avoid any delay in establishing satisfactory oxygenation, as well as satisfactory nutrition (Cornblath et al., 1966).

We are grateful to the paediatric residents who carried out the initial care; to the nurses who recorded the clinical condition of the babies; and to the pathologists who carried out the necropsy examinations, many of which were performed or supervised by Drs. G. S. Anderson or W. Aherne. Miss Judith Marr, medical student, helped in the analysis in the first investigation.

\section{REFERENCES}

Avery, M. E. (1968). The Lung and its Disorders in the Newborn Infant, 2nd ed. Saunders, Philadelphia, London, and Toronto.

Cohen, M. M., Weintraub, D. H., and Lilienfeld, A. M. (1960). The relationship of pulmonary hyaline membrane to certain factors in pregnancy and delivery. Pediatrics, 26, 42.

Cornblath, M., Forbes, A. E., Pildes, R. S., Luebben, G., and Greengard, J. (1966). A controlled study of early fluid administration on survival of low birth weight infants. Pediatrics, 38, 547.

Fairweather, D. V. I., Russell, J. K., Anderson, G. S., Bird, T., Millar, D. G., and Pearcy, P. A. M. (1966). Perinatal mortality in Newcastle upon Tyne 1960-62. Lancet, 1, 140.

Fedrick, J., and Butler, N. R. (1970). Certain causes of neonatal death. I. Hyaline membranes. Biology of the Neonate, 15, 229.

James, L. S. (1959). Physiology of respiration in newborn infants and in the respiratory distress syndrome. Pediatrics, 24, 1069.

Miller, H. C. (1962). Respiratory distress syndrome of newborn infants. II. Clinical study of pathogenesis. Fournal of Pediatrics, 61, 9.

Neligan, G. A., Robson, E., and Hey, E. (1969). Hyaline membrane disease in twins. Pediatrics, 43, 143.

Reynolds, E. O. R., Jacobson, H. N., Motoyama, E. K., Kikkawa, Y., Craig, J. M., Orzalesi, M. M., and Cook, C. D. (1965). The effect of immaturity and prenatal asphyxia on the lungs and pulmonary function of newborn lambs: the experimental production of respiratory distress. Pediatrics, 35, 382.

Rokos, J., Vaeusorn, O., Nachman, R., and Avery, M. E. (1968). Hyaline membrane disease in twins. Pediatrics, 42, 204.

Rudolph, A. J., and Smith, C. A. (1960). Idiopathic respiratory distress syndrome of the newborn. Fournal of Pediatrics, 57, 905.

Correspondence to Dr. G. A. Neligan, Princess Mary Maternity Hospital, Great North Road, Newcastle upon Tyne NE2 3BD. 